ARTICLE

DOI: $10.1038 / s 41467-018-04788-3$

\title{
Anion insertion enhanced electrodeposition of robust metal hydroxide/oxide electrodes for oxygen evolution
}

\author{
Zhenhua Yan (10 ${ }^{1}$, Hongming Sun ${ }^{1}$, Xiang Chen ${ }^{1}$, Huanhuan Liu', Yaran Zhao ${ }^{1}$, Haixia Li ${ }^{1}$, Wei Xie ${ }^{1}$, \\ Fangyi Cheng ${ }^{1}{ }^{1} \&$ Jun Chen ${ }^{1,2}$
}

Electrochemical deposition is a facile strategy to prepare functional materials but suffers from limitation in thin films and uncontrollable interface engineering. Here we report a universal electrosynthesis of metal hydroxides/oxides on varied substrates via reduction of oxyacid anions. On graphitic substrates, we find that the insertion of nitrate ion in graphene layers significantly enhances the electrodeposit-support interface, resulting in high mass loading and super hydrophilic/aerophobic properties. For the electrocatalytic oxygen evolution reaction, the nanocrystalline cerium dioxide and amorphous nickel hydroxide co-electrodeposited on graphite exhibits low overpotential (177 mV@10 mA cm ${ }^{-2}$ ) and sustains long-term durability (over $300 \mathrm{~h}$ ) at a large current density of $1000 \mathrm{~mA} \mathrm{~cm}{ }^{-2}$. In situ Raman and operando X-ray diffraction unravel that the integration of cerium promotes the formation of electrocatalytically active gamma-phase nickel oxyhydroxide with exposed (003) facets. Therefore, combining anion intercalation with cathodic electrodeposition allows building robust electrodes with high electrochemical performance.

\footnotetext{
${ }^{1}$ Key Laboratory of Advanced Energy Materials Chemistry (Ministry of Education), College of Chemistry, Nankai University, Tianjin 300071, China.

${ }^{2}$ Collaborative Innovation Center of Chemical Science and Engineering, Nankai University, Tianjin 300071, China. Correspondence and requests for materials should be addressed to F.C. (email: fycheng@nankai.edu.cn)
} 
E lectrodeposition is a conventional, useful technology to prepare thin films of functional materials such as metal/ alloy plating and oxide/chalcogenide semiconductors ${ }^{1-6}$. In particular, there is an increasing interest in direct electrodepositing electrochemically active materials on conducting substrates for electrocatalysis, battery, and supercapacitor applications $^{7-10}$. The electrodeposited freestanding electrodes possess advantageous active site utilization and simple fabrication over the conventional powder form, which is physically mixed with polymeric binder and conducting agent to make a slurry for coating on current collector ${ }^{11}$. However, electrosynthesis is often limited in the formation of thin film due to weak deposit-substrate interaction, insufficient mass transport to the electrode surface, unwanted blocking of evolved gas, low nucleation rate, and high resistance of the deposit ${ }^{12-15}$. Despite progress in fabrication of thick layer on three-dimensional (3D) porous matrix (e.g., $\mathrm{Zn}, \mathrm{MnO}_{2} / \mathrm{Ni}$ foam, and $\mathrm{Nb}_{2} \mathrm{O}_{5} /$ graphene $)^{16-18}$, it is difficult to achieve high loading on flat substrates and the substrate-deposit interface effect remains elusive. Furthermore, electrodeposition of a target material proceeds via a specific anodic or cathodic reaction involving selected precursor, posing great challenge in universality of the synthesis.

The oxygen evolution reaction (OER) plays a key role in developing clean energy conversion and storage technologies, as it generates electrons that can reduce water to hydrogen, carbon dioxide to carbon-containing fuels, and metal ions to metal in recharge of metal-air batteries ${ }^{19-22}$. Industrial application of OERrelated devices relies on the use of low-cost, abundant and efficient electrocatalysts to promote the sluggish process involving fourelectron transfer ${ }^{8,23}$. Alternative to the state-of-the-art Ru and Irbased materials, substantial advances have been made in exploiting nonprecious oxygen-evolving catalysts, among which some firstrow transition metal hydr(oxy)oxides/oxides show superior intrinsic activity ${ }^{24-29}$. Ultrathin film electrodes exhibit high gravimetric specific activity but cannot afford large current due to the limited amount of active sites. Increasing mass loading is a feasible way to achieve high current at moderate overpotentials ${ }^{30}$ but would hamper mass transport and charge transfer. Another difficulty to operate at high OER currents concerns the rigorous bubble release, which causes bubble-shielding effect and catalyst peeling off problem ${ }^{7,31}$. There remains formidable challenge in improving the activity and robustness of OER catalysts at current densities up to $1000 \mathrm{~mA} \mathrm{~cm}^{-2}$. It is desirable to build selfsupporting electrodes with high catalyst loading, abundant active sites, and super hydrophilic/aerophobic properties by interfacial engineering.

Here, we report a general strategy to incorporate a variety of metal (including IIA, IIB, IIIB, VIB, and VIII elements) hydroxides/oxides into graphitic substrates by leveraging anion intercalation and cathodic electrodeposition. Various metal hydroxides/oxides can be synthesized by increasing cathode surface $\mathrm{pH}$ with oxyacid anions reduction. The coelectrodeposition of $\mathrm{Ni}$ hydroxide and $\mathrm{Ce}$ oxide on graphite support generates robust and homogeneous catalyst layers through anion insertion in graphene layers, eliminating the need of binders. As an exemplified application, $\mathrm{NiCeO}_{x} \mathrm{H}_{y} /$ graphite serves as an electrocatalytic electrode with high OER performance surpassing the state-of-the-art $\mathrm{RuO}_{2}$ benchmark and superior stability at large current densities. A combination of in situ Raman and operando X-ray diffraction (XRD) further reveals that electrocatalytically active $\gamma-\mathrm{NiOOH}$ with exposed (003) facets forms on $\mathrm{NiCeO}_{x} \mathrm{H}_{y}$ at low overpotentials. These findings would enlighten the interface-controllable electrosynthesis of advanced electrodes viable to industrial applications.

\section{Results}

Anion intercalation enhanced electrodeposition synthesis. To synthesize metal hydroxides, we applied the cathodic electrodeposition, which has been widely used in plating metal coatings. Cathodic reactions such as oxyacid anion reduction generate hydroxide ions (e.g., Eqs. (1)-(3)) and give rise to an increase of $\mathrm{pH}$ value close to the cathode surface. For most metals, the standard potentials $\left(E^{\theta}\right)$ of reactions $(1-3)$ are higher than those of the cation reductions. Based on Pourbaix diagram (example of $\mathrm{Ni}$ species shown in Supplementary Fig. 1) $)^{32}$, the generated species is thermodynamically controlled by parameters of applied potential, cation concentration, and $\mathrm{pH}$ value. Cathodic reduction increases the local $\mathrm{pH}$ value near the electrode and thereby kinetically drives the deposition of metal hydroxides and in some cases metal oxides when hydroxide is further dehydrated or oxidized in air. Notably, the cathodic electrosynthesis also favors the coprecipitation of bi-metallic or multi-metallic hydroxides.

$$
\begin{array}{rr}
\mathrm{ClO}_{3}^{-}+3 \mathrm{H}_{2} \mathrm{O}+6 \mathrm{e}^{-} \rightarrow \mathrm{Cl}^{-}+6 \mathrm{OH}^{-} & E^{\theta}=1.890 \mathrm{~V} \\
\mathrm{IO}_{3}^{-}+3 \mathrm{H}_{2} \mathrm{O}+6 \mathrm{e}^{-} \rightarrow \mathrm{I}^{-}+6 \mathrm{OH}^{-} & E^{\theta}=1.088 \mathrm{~V} \\
\mathrm{NO}_{3}^{-}+\mathrm{H}_{2} \mathrm{O}+2 \mathrm{e}^{-} \rightarrow \mathrm{NO}_{2}^{-}+2 \mathrm{OH}^{-} & E^{\theta}=0.838 \mathrm{~V}
\end{array}
$$

The substrate plays a prominent effect on the interface property and the mass loading of the metal hydroxide deposit. Graphitic materials are found to be particularly beneficial in present cathodic electrodeposition as the graphene interlayer accommodates anions ${ }^{33,34}$ and thereby enhances substrate-deposit interaction. To take advantage of the anion intercalation, we adopted a two-step deposition, as illustrated in Fig. 1a. First, a positive potential was applied to facilitate the insertion of $\mathrm{NO}_{3}{ }^{-}$ions into the graphite lattice via electrostatic attraction. Then, the current was reversed to allow cathodic reduction and simultaneous electrodeposition (Fig. 1b), which resulted in the generation of graphite-supported metal hydroxide film. Intercalation of $\mathrm{NO}_{3}{ }^{-}$in graphite was evidenced by a combination of XRD, Fourier-transform infrared spectroscopy (FTIR), and Raman analysis (Supplementary Fig. 2), which revealed a shift of (002) diffraction peak with intensity decrease, the presence of characteristic $\mathrm{NO}_{3}{ }^{-}$signature at $1380 \mathrm{~cm}^{-1}$, as well as the peak shift of $G$ band from 1585 to $1605 \mathrm{~cm}^{-1}$ and the

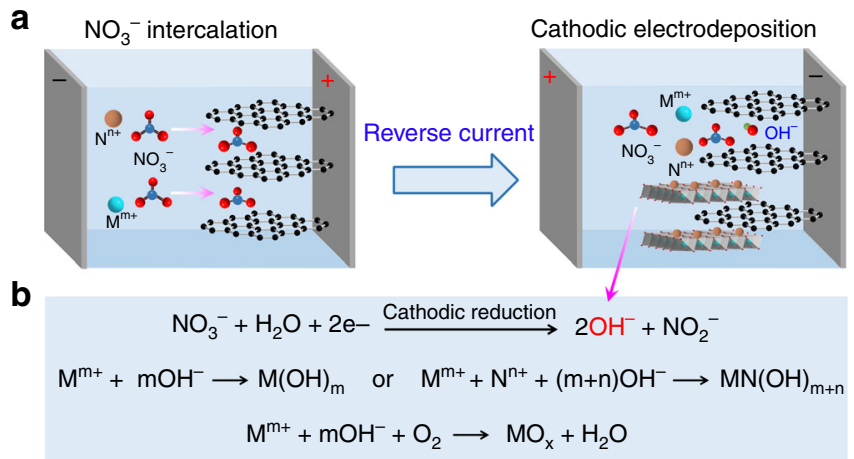

Fig. 1 Electrodeposition strategy and principles. a A schematic two-step synthesis using graphite $(G)$ substrate and nitrate precursors. b The reaction mechanisms of the cathodic electrodeposition of metal hydroxides $\left(\mathrm{M}(\mathrm{OH})_{m}\right.$ or $\left.\mathrm{MN}(\mathrm{OH})_{m+n}\right)$, and oxides $\left(\mathrm{MO}_{x}\right) \cdot \mathrm{M}^{\mathrm{m}+}$ and $\mathrm{N}^{\mathrm{n}+}$ are metal cations 


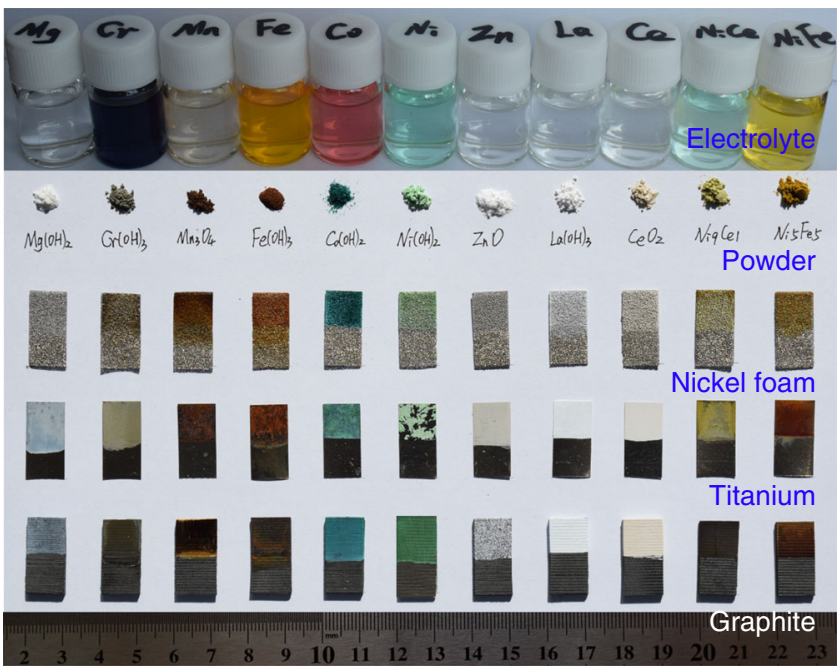

Fig. 2 Universality of the cathodic electrodeposition. Optical photographs of the electrolyte precursors, the corresponding generated samples on different substrates, and the collected powders from Ti foil. Each electrodeposition was performed by applying a constant current density of $-20 \mathrm{~mA} \mathrm{~cm}^{-2}$ for $300 \mathrm{~s}$ in $0.1 \mathrm{M}$ metal nitrate electrolyte

appearance of $\mathrm{D}$ band at $1355 \mathrm{~cm}^{-1}$, respectively. The intercalation of metal cation could be negligible in anodic treatment at positive potentials due to electrostatic repulsion but would favor the generation of metal hydroxide in the cathodic electrodeposition.

The cathodic electrodeposition is a general, efficient strategy to prepare hydroxides of different metals on a variety of conducting substrates. We selected alkaline earth metal $(\mathrm{Mg}), 3 d$ transition metals (Cr, Mn, Fe, Co, Ni, and $\mathrm{Zn}$ ), and lanthanides ( $\mathrm{La}$ and $\mathrm{Ce}$ ) as examples to demonstrate the universality of the synthesis. Figure 2 shows the digital photos of a series of $0.1 \mathrm{M}$ metal nitrate solutions and the corresponding deposited samples. Powder XRD (Supplementary Fig. 3) analysis indicates the formation of crystalline hydroxides/oxides, including $\mathrm{Mg}(\mathrm{OH})_{2}$ (Joint Committee on Powder Diffraction Standards JCPDS \#7-239), $\mathrm{Cr}(\mathrm{OH})_{3}$ (\#12-241), $\mathrm{Co}(\mathrm{OH})_{2}$ (\#30-443), $\mathrm{La}(\mathrm{OH})_{3} \quad$ (\#83-2034), $\mathrm{Mn}_{3} \mathrm{O}_{4}$ (\#16-154), $\mathrm{ZnO}$ (\#89-511), and $\mathrm{CeO}_{2}$ (\#81-792). Other hydroxides such as the obtained $\mathrm{Ni}(\mathrm{OH})_{2}, \mathrm{Fe}(\mathrm{OH})_{3}$, and bimetallic $\mathrm{Ni}-\mathrm{Ce}$ (denoted as $\mathrm{NiCeO}_{x} \mathrm{H}_{y}$ ) feature poor crystallinity or amorphous form. The morphology and size of the electrodeposited samples can be viewed from scanning electron microscopy (SEM) images (Supplementary Fig. 4), which present different shapes including nanosheets $\left(\mathrm{Mg}(\mathrm{OH})_{2}, \mathrm{Co}(\mathrm{OH})_{2}\right.$, and $\left.\mathrm{NiFeO}_{x} \mathrm{H}_{y}\right)$ and aggregated nanoparticles $\left(\mathrm{Cr}(\mathrm{OH})_{3}, \mathrm{Mn}_{3} \mathrm{O}_{4}\right.$, $\mathrm{Fe}(\mathrm{OH})_{3}, \mathrm{ZnO}$, and $\left.\mathrm{La}(\mathrm{OH})_{3}\right)$.

Benefiting from the cathode reduction process without oxidizing corrosion, common metals (e.g., $\mathrm{Fe}, \mathrm{Cu}, \mathrm{Ni}$, and $\mathrm{Ti}$ ) and electroconductive materials (e.g., carbon, indium tin oxide, and fluorine-doped tin oxide) can serve as the substrates. We comparatively demonstrate the electrodeposition of metal hydroxides/oxides on 3D (carbon paper CP and nickel foam NF) and two-dimensional (2D) ( $\mathrm{Ti}$ and graphite sheet) supports. The deposits show super hydrophilicity, in contrast with the hydrophobic properties of the substrates (Supplementary Fig. 5). On flat Ti substrate, powdery samples can be easily scraped off from the surface. On $3 \mathrm{D} \mathrm{NF}$ and $\mathrm{CP}$ substrates, a preultrasonication treatment in electrolyte results in uniform coating and deep electrodeposition inside the porous skeleton (Supplementary Fig. 6). Interestingly, firm deposit adherence is observed on graphite substrate, which differs from weak binding on other smooth surfaces such as glass carbon (GC), copper, and conducting tin oxides.

Characterization of electrodeposited hydroxides/oxides. In a representative example of $\mathrm{Ni}-\mathrm{Ce}$ codeposition, the generated deposit was firmly supported on the graphite substrate without apparent interspace, as shown in the SEM image (Fig. 3a). Elemental mapping clearly showed penetration of $\mathrm{Ni}, \mathrm{Ce}$, and $\mathrm{O}$ into graphite (Fig. 3b). The firm deposit-substrate interaction was further evidenced by high-resolution transmission electron microscope (HRTEM) imaging (Supplementary Fig. 7), which showed anchoring of $\mathrm{NiCeO}_{x} \mathrm{H}_{y}$ nanoparticles on graphite layers. In comparison, the electrodeposition without a foregoing anionintercalation process generated a clear gap between the hydroxide deposit and the graphite substrate (Fig. $3 c$ and Supplementary Fig. 8). This shaky deposit film would hinder the electrical conductivity and mechanical robustness. Electrochemical impedance spectroscopy suggested a drastically lower interface resistance of the $\mathrm{NiCeO}_{x} \mathrm{H}_{y} /$ graphite electrode because of the interface enhancement by nitrate insertion in the substrate (Supplementary Fig. 9).

Another virtue of the nitrate-assisted cathodic electrodeposition is the capability to attain high mass loading of deposits, circumventing the thin film limitation in conventional electrochemical synthesis. The amount of deposit could be easily controlled by electrodeposition time at a constant applied current density. As shown in Fig. 3d, for $\mathrm{Ni}$ and Ce co-deposition on 2D graphite as well as $3 \mathrm{D}$ porous $\mathrm{NF}$ and $\mathrm{CP}$ substrates, the loading mass increased linearly to $23 \mathrm{mg} \mathrm{cm}^{-2}$ with deposition time. For graphite substrate, the loading mass ( $m$ in $\mathrm{mg}$ ) and deposition time ( $t$ in s) follows a linear relationship of $m=0.01599 t+$ 0.3051. Similar behaviors were observed for the deposition of individual $\mathrm{Ni}$ or Ce hydroxide/oxide (Supplementary Fig. 10). High mass loading along with controllable deposition is desirable for scaled-up production and applications in electrochemical devices such as electrolyzers, supercapacitors and batteries. Note that this cathodic electrodeposition on smooth non-graphitic $2 \mathrm{D}$ substrates (such as $\mathrm{GC}, \mathrm{Ti}, \mathrm{Cu}$, and conductive glass) remains limited in mass loading control due to weak deposit-support adhesion in the absence of anion intercalation.

Low-magnification SEM images (Fig. 3a and Supplementary Fig. 11) show interconnected cracks in the electrodeposited electrodes. The formation of cracks results from the evaporation of water trapped in the deposits, as seen from the evolution of optical microscope photos during the air-dry process (Supplementary Fig. 12). Magnified imaging (Fig. 4a) reveals that the deposit layer is composed of aggregated nanoparticles with interparticle pores. This rimous texture favors the infiltration of electrolyte inside the electrode, thereby increasing the utilization of active mass. A combination of HRTEM (Fig. $4 \mathrm{~b}$ and Supplementary Fig. 13), selected-area electron diffraction (SAED) (Fig. 4b, inset) and XRD (Supplementary Fig. 14a) further indicates that the deposited $\mathrm{NiCeO}_{x} \mathrm{H}_{y}$ hybrid consists of ultrasmall crystalline $\mathrm{CeO}_{2}$ nanoparticles (typical size $3.5 \mathrm{~nm}$ ) and amorphous $\mathrm{Ni}(\mathrm{OH})_{2}$. The uniform distribution of nanocrystalline $\mathrm{CeO}_{2}$ in $\mathrm{Ni}(\mathrm{OH})_{2}$ matrix forms a mosaic structure. The composition of the $\mathrm{NiCeO}_{x} \mathrm{H}_{y}$ hybrid can be well regulated by adjusting the feeding Ni:Ce ratio in the precursor electrolyte. In a typical hybrid sample, a $\mathrm{Ni}: \mathrm{Ce}$ atomic ratio of 9:1 was estimated by energy dispersive spectroscopy (EDS) (Supplementary Fig. 14b). Thermogravimetric analysis further indicates that water accounts for $9.9 \mathrm{wt} \%$ in the $\mathrm{NiCeO}_{x} \mathrm{H}_{y}$ hybrid (Supplementary Fig. 15).

The FTIR spectra of the Ni, Ce, and Ni-Ce deposits (Fig. 4c) present bands at 3425 and $1630 \mathrm{~cm}^{-1}$, which are assigned to the stretching modes of absorbed water ${ }^{35}$. Characteristic peaks of 

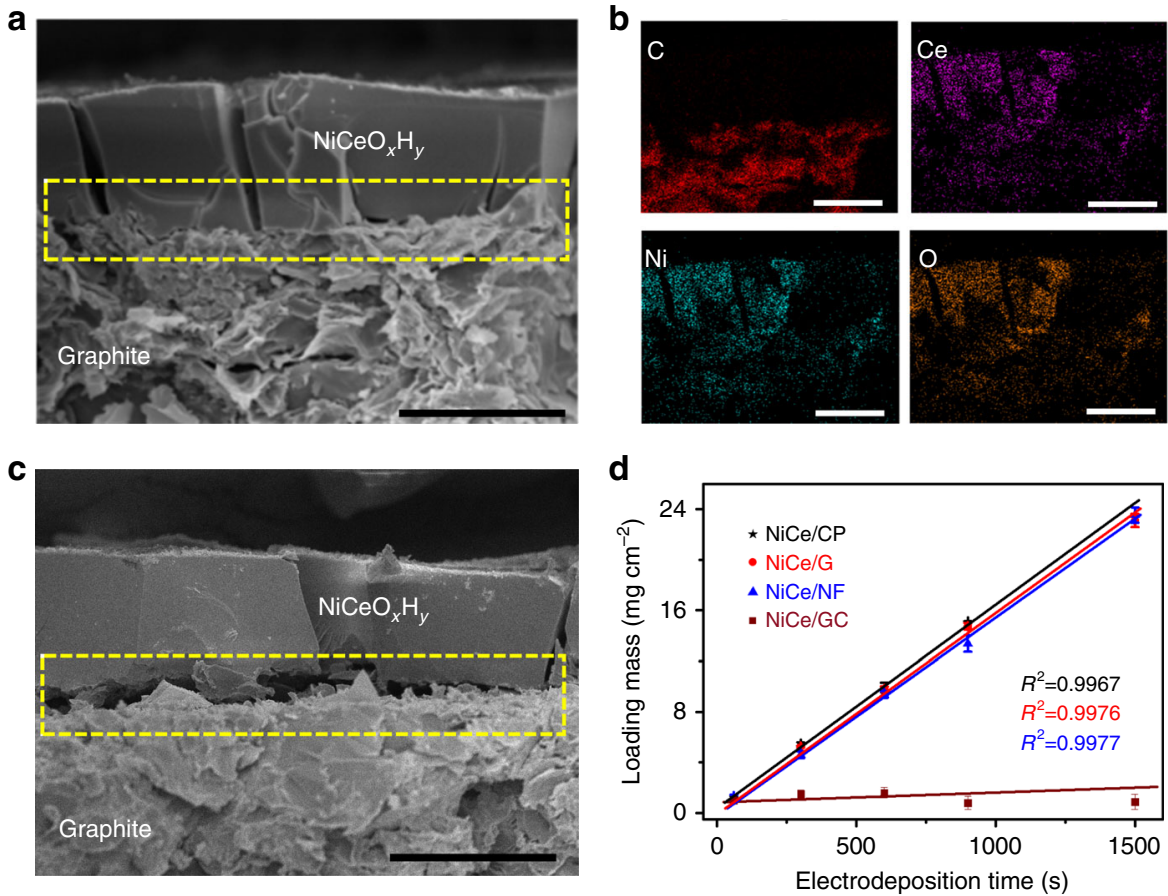

Fig. 3 Enhanced electrodeposition on nitrate-inserted graphite. a Cross-section SEM image of the prepared $\mathrm{NiCeO}_{x} \mathrm{H}_{y}$ deposited on graphite after nitrate ion insertion. b Elemental mapping of $\mathrm{C}, \mathrm{Ce}, \mathrm{Ni}$, and $\mathrm{O}$. c Cross-section $\mathrm{SEM}$ image of $\mathrm{NiCeO}_{x} \mathrm{H}_{y}$ directly deposited on graphite without foregoing anion intercalation. Scale bars, $25 \mu \mathrm{m}$. d Relationship between the electrodeposition time and the loading mass of $\mathrm{NiCeO}_{x} \mathrm{H}_{y}$ deposited on carbon paper (CP), graphite (G), nickel foam (NF), and glass carbon (GC). The electrodeposition was performed at a current density of $-20 \mathrm{~mA} \mathrm{~cm}{ }^{-2}$ in electrolyte containing totally $0.1 \mathrm{M} \mathrm{Ni}$ and $\mathrm{Ce}$ nitrates
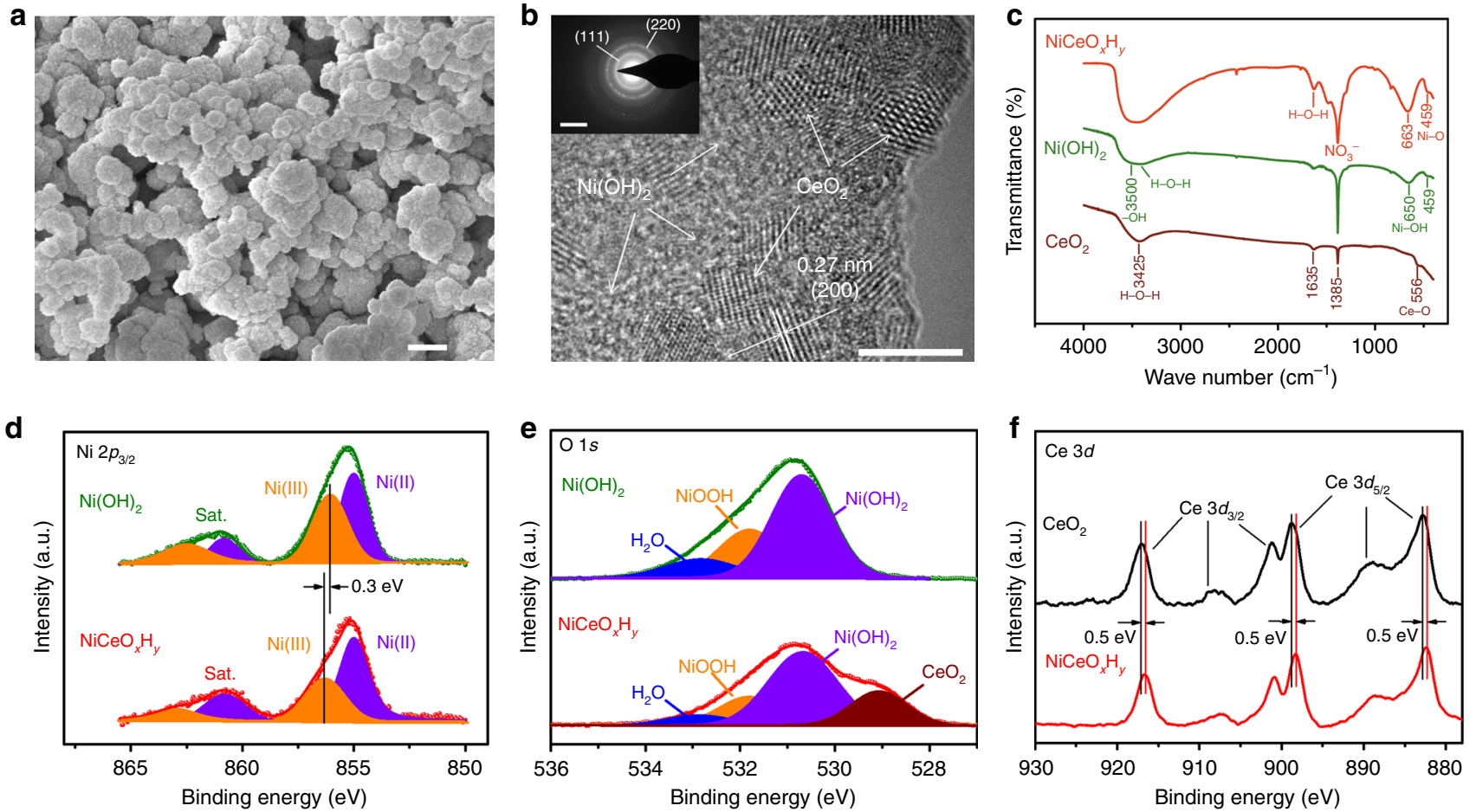

Fig. 4 Materials characterization of electrodeposits. a SEM (scale bar: $200 \mathrm{~nm}$ ) and b HRTEM (scale bar: $5 \mathrm{~nm}$ ) images of $\mathrm{NiCeO}_{x} \mathrm{H}_{y}$. The inset shows SAED pattern (scale bar: 5 1/nm). c FTIR spectra of powdery $\mathrm{NiCeO}_{x} \mathrm{H}_{y,} \mathrm{Ni}(\mathrm{OH})_{2}$, and $\mathrm{CeO}_{2}$. d, e XPS spectra of powdery $\mathrm{Ni}(\mathrm{OH})_{2}$ and $\mathrm{NiCeO} \mathrm{H}_{y}$. f $\mathrm{Ce} 3 d$ XPS spectra of $\mathrm{CeO}_{2}$ and $\mathrm{NiCeO}_{x} \mathrm{H}_{y}$ 
$\mathrm{NO}_{3}{ }^{-}$at $1385 \mathrm{~cm}^{-1}$ originated from the nitrate-assisted cathodic electrodeposition. The broad band centered at around $3500 \mathrm{~cm}^{-1}$ and the weak peak at $1296 \mathrm{~cm}^{-1}$ correspond to the $-\mathrm{OH}$ stretching vibration of $\mathrm{NiCeO}_{x} \mathrm{H}_{y}$ and $\mathrm{Ni}(\mathrm{OH})_{2}$. There is a blue shift $\left(\mathrm{ca} .13 \mathrm{~cm}^{-1}\right)$ of the $\mathrm{Ni}-\mathrm{OH}$ bending vibration of $\mathrm{NiCeO}_{x} \mathrm{H}_{y}$ relative to $\mathrm{Ni}(\mathrm{OH})_{2}$, which could be attributed to the change of $\mathrm{Ni}$ local environment by $\mathrm{CeO}_{2}$ hybridization. Raman spectra (Supplementary Fig. 16) show a broad peak in the range of $420-520 \mathrm{~cm}^{-1}$, which could be attributed to $\mathrm{Ni}-\mathrm{O}$ and $\mathrm{Ce}-\mathrm{O}$ bands ${ }^{36}$. The appearance of a new vibration at ca. $613 \mathrm{~cm}^{-1}$ in $\mathrm{NiCeO}_{x} \mathrm{H}_{y}$ further evidences the $\mathrm{Ni}-\mathrm{O}-\mathrm{Ce}$ interaction.

$\mathrm{X}$-ray photoelectron spectroscopy (XPS) was performed to probe the oxidation states of $\mathrm{Ni}$ and $\mathrm{Ce}$ in the electrodeposits. As shown in the Ni $2 p_{3 / 2}$ spectra (Fig. $4 \mathrm{~d}$ ), both $\mathrm{Ni}-\mathrm{Ce}$ hybrid and $\mathrm{Ni}$ hydroxide contain $\mathrm{Ni}(\mathrm{II})$ (at $855 \mathrm{eV}$ ) and $\mathrm{Ni}(\mathrm{III})$ species $(856.4$ and $856.1 \mathrm{eV}$ ). There is a positive shift of $0.3 \mathrm{eV}$ for $\mathrm{Ni}$ (III) in the $\mathrm{Ni}-\mathrm{Ce}$ hybrid. Fitting the $\mathrm{O} 1 s$ spectrum (Fig. $4 \mathrm{e}$ ) of $\mathrm{NiCeO}_{x} \mathrm{H}_{y}$ shows deconvoluted peaks at 529, 530.6, 531.8, and $532.8 \mathrm{eV}$, which are assignable to $\mathrm{CeO}_{2}, \mathrm{Ni}(\mathrm{OH})_{2}, \mathrm{NiOOH}$, and $\mathrm{H}_{2} \mathrm{O}$, respectively ${ }^{37,38}$. For $\mathrm{Ce} 3 d$ spectra of $\mathrm{CeO}_{2}$ and $\mathrm{NiCeO}_{x} \mathrm{H}_{y}$ (Fig. 4f), six peaks located at above $881 \mathrm{eV}$ are characteristic of Ce (IV) ${ }^{39}$. All the Ce $3 d$ peaks in hybrid $\mathrm{NiCeO}_{x} \mathrm{H}_{y}$ negatively shifts by $0.5 \mathrm{eV}$ as compared to that of $\mathrm{CeO}_{2}$. The positive shift of $\mathrm{Ni}$ binding energy along with the negative shift of $\mathrm{Ce}$ position indicate electron transfer from $\mathrm{Ni}$ to $\mathrm{Ce}$ in the $\mathrm{Ni}-\mathrm{Ce}$ hybrid, which can be interpreted by the higher electron affinity of Ce(IV). The uniform distribution of $\mathrm{CeO}_{2}$ and $\mathrm{Ni}(\mathrm{OH})_{2}$ phases and firm interparticle contact in the mosaic structure of the hybrid (Fig. 4b) could benefit the $\mathrm{Ni}-\mathrm{Ce}$ electronic interaction.

Electrocatalytic OER on electrodeposited electrodes. As an exemplified application, the electrodeposited hydroxides were investigated towards the OER electrocatalysis. Figure 5a shows a

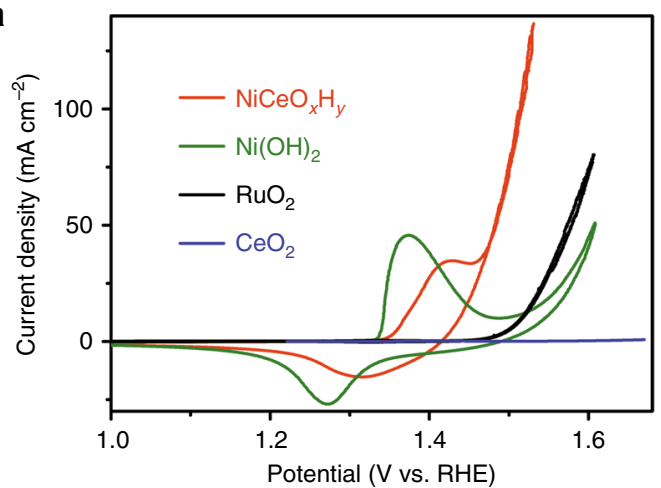

b
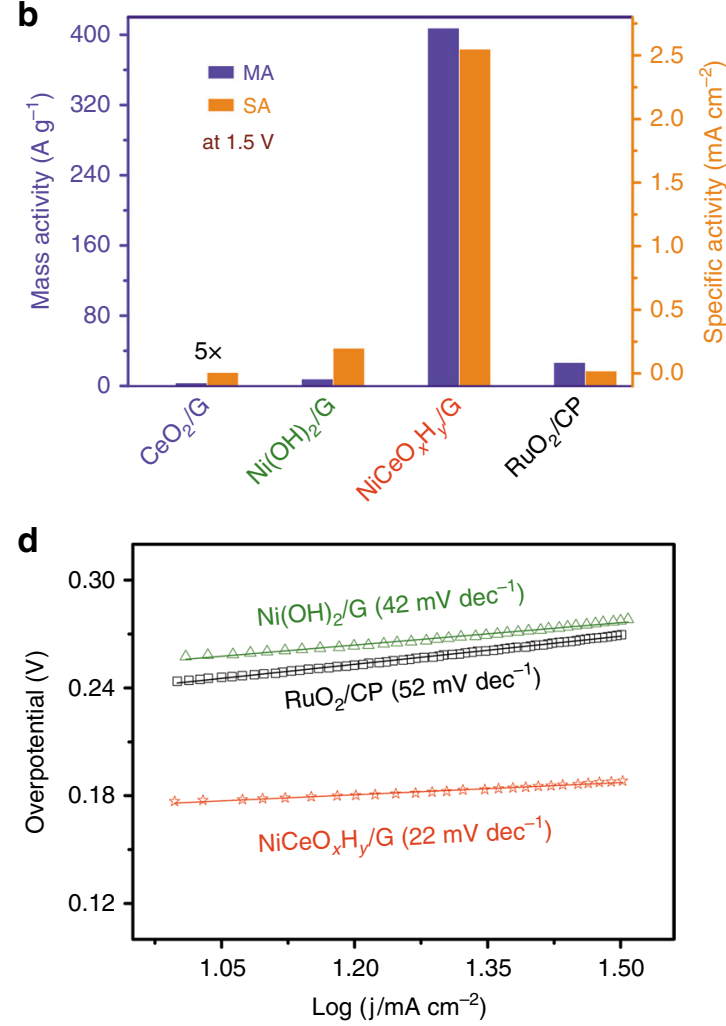
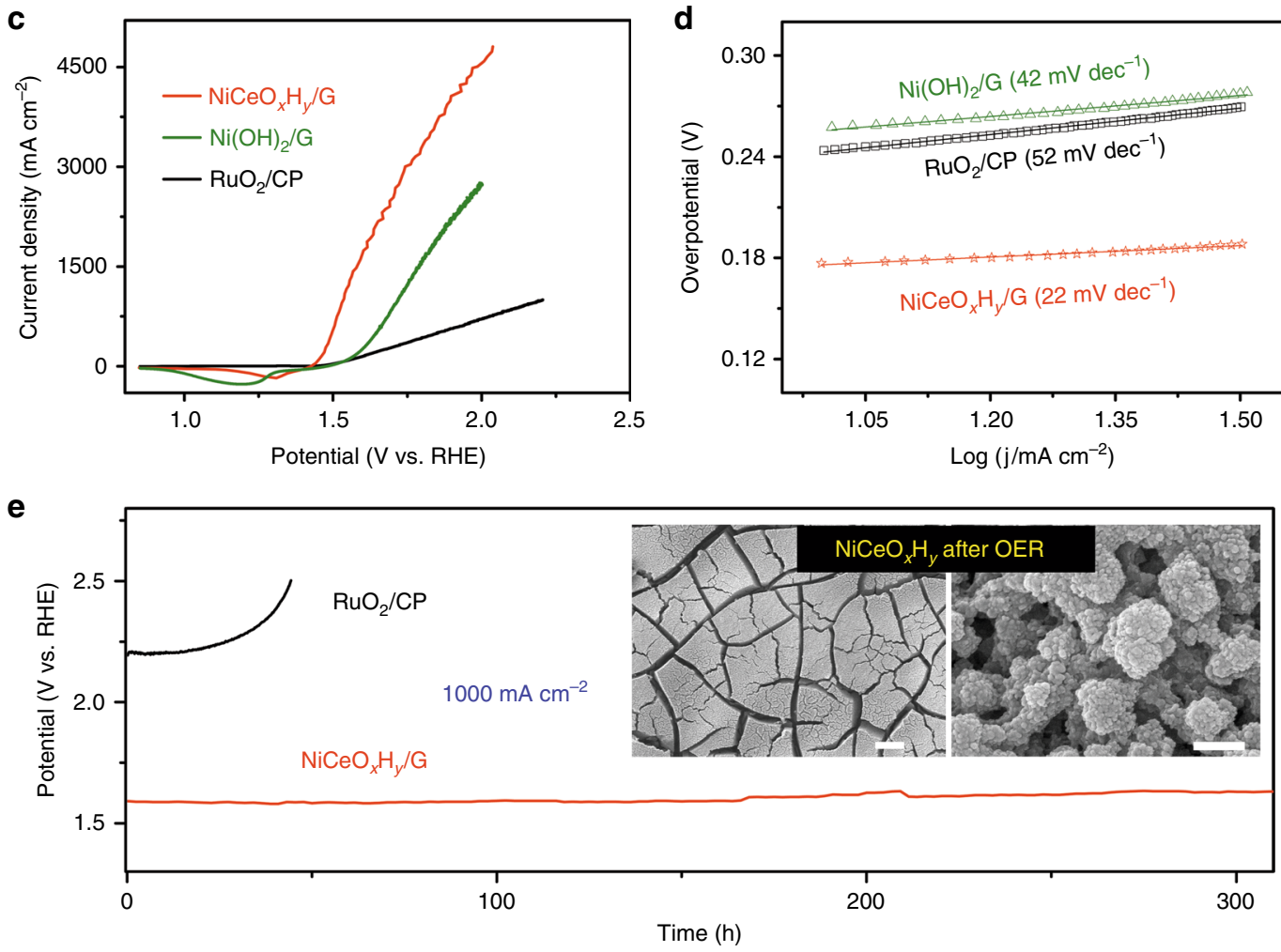

Fig. 5 Electrocatalytic OER performance in $1.0 \mathrm{M} \mathrm{KOH}$ electrolyte. a Voltammetry (scan rate $10 \mathrm{mV} \mathrm{s}^{-1}$ ) of $\mathrm{NiCeO}_{x} \mathrm{H}_{y}, \mathrm{Ni}(\mathrm{OH})_{2}, \mathrm{CeO}_{2}$, and RuO $\mathrm{Rupported}_{2}$ on rotational disk electrode with mass loading of $0.2 \mathrm{mg} \mathrm{cm}^{-2}$. b Mass and specific activities derived from (a) at $1.5 \mathrm{~V}$. The data of $\mathrm{CeO}_{2} / \mathrm{G}$ are multiplied by 5 for clear display. c Polarization curves (scan rate $10 \mathrm{mV} \mathrm{s}^{-1}$ ) of $\mathrm{NiCeO}_{x} \mathrm{H}_{y} / \mathrm{G}, \mathrm{Ni}(\mathrm{OH})_{2} / \mathrm{G}$, and $\mathrm{RuO}_{2} / \mathrm{CP}$ electrodes with mass loading of 10 , 10 , and $6 \mathrm{mg} \mathrm{cm}^{-2}$, respectively. $\mathbf{d}$ Tafel plots derived from the curves in (c). e Chronopotentiometry of $\mathrm{RuO}_{2} / \mathrm{CP}$ and $\mathrm{NiCeO}_{x} \mathrm{H}_{y} / \mathrm{G}$ at a current density of $1000 \mathrm{~mA} \mathrm{~cm}^{-2}$. Inset shows the SEM images (scale bar: left $20 \mu \mathrm{m}$, right $200 \mathrm{~nm}$ ) of the $\mathrm{NiCeO}_{x} \mathrm{H}_{y} / \mathrm{G}$ electrode after OER test at $1000 \mathrm{~mA} \mathrm{~cm}{ }^{-2}$ for $300 \mathrm{~h}$ 
the representative cyclic voltammograms (CVs) of $\mathrm{Ni}-\mathrm{Ce}$ hybrid, $\mathrm{Ni}(\mathrm{OH})_{2}, \mathrm{CeO}_{2}$, and $\mathrm{RuO}_{2}$ supported on graphite-modified GC electrode in rotating disk electrode (RDE) testing mode. The curve of $\mathrm{Ni}(\mathrm{OH})_{2}$ presents a redox couple peaked around $1.27 / 1.37 \mathrm{~V}$ and a rapid rising of anodic current at potentials higher than $1.50 \mathrm{~V}$. The redox couple are attributed to the conversion between $\mathrm{Ni}(\mathrm{OH})_{2}$ and $\mathrm{NiOOH}$ in alkaline electrolytes ${ }^{40}$ while the anodic response corresponds to oxygen evolving. $\mathrm{NiCeO}_{x} \mathrm{H}_{y}$ displays similar profiles but more overlapping of $\mathrm{Ni}^{2+}$ oxidation and OER process. To minimize the masking effect of the preoxidation, we derived the Tafel plots and compared the OER activities using the cathodic sweep.

Remarkably, the $\mathrm{NiCeO}_{x} \mathrm{H}_{y}$ hybrid exhibited a low onset overpotential of $180 \mathrm{mV}$ and required only $207 \mathrm{mV}$ overpotential to reach a current density of $10 \mathrm{~mA} \mathrm{~cm}^{-2}$ (Fig. 5a). This performance is superior to the benchmark $\mathrm{RuO}_{2}$. The difference in OER activity can be further viewed from the Tafel plots of the electrodes (Supplementary Fig. 17). At a given potential of $1.5 \mathrm{~V}$, the mass activity (current density normalized by catalyst mass) of $\mathrm{NiCeO}_{x} \mathrm{H}_{y}$ is $406.8 \mathrm{~A} \mathrm{~g}^{-1}, 57$ and 15 times that of $\mathrm{Ni}(\mathrm{OH})_{2}$ and $\mathrm{RuO}_{2}$, respectively (Fig. 5b). The corresponding specific activity (current density based on electrochemically active surface area (ECSA), Supplementary Figs. 18,19$)$ of $\mathrm{NiCeO}_{x} \mathrm{H}_{y} / \mathrm{G}$ is 2.5 $\mathrm{mA} \mathrm{cm}{ }^{-2}$, 185 times higher than that of the benchmark $\mathrm{RuO}_{2}$. While $\mathrm{CeO}_{2}$ was almost electrocatalytic inactive, the neat $\mathrm{Ni}(\mathrm{OH})_{2}$ electrode showed a considerably low overpotential of $320 \mathrm{mV}$ at 10 $\mathrm{mA} \mathrm{cm}^{-2}$, which could be attributed to the self-supporting electrode structure that negates the use of binder. Supplementary Fig. 20 clearly reveals the superiority of electrodeposited electrode over the comparative electrodes made by coating a physically mixed powdery catalysts with conducting additive and polymeric binder.

The amount of coated catalyst is limited on GC substrate due to weak affinity. Benefiting from the strong deposit-substrate interaction, the $\mathrm{NiCeO}_{x} \mathrm{H}_{y} / \mathrm{G}$ electrode could afford a high mass loading over $15 \mathrm{mg} \mathrm{cm}^{-2}$ (Supplementary Fig. 21). At an optimized loading of $10 \mathrm{mg} \mathrm{cm}^{-2}$, the electrode exhibits excellent performance (Fig. 5c). A current density of $10 \mathrm{~mA} \mathrm{~cm}^{-2}$ was attained at a low overpotential of $177 \mathrm{mV}$. A moderate overpotential of $500 \mathrm{mV}$ rendered a large current of $3000 \mathrm{~mA} \mathrm{~cm}^{-2}$. As shown in Fig. 5 d, the $\mathrm{NiCeO}_{x} \mathrm{H}_{y} / \mathrm{G}$ electrode gave a Tafel slope of $22 \mathrm{mV} \mathrm{dec}^{-1}$, much lower than those of $\mathrm{Ni}(\mathrm{OH})_{2}(42 \mathrm{mV} \mathrm{dec}$ ${ }^{-1}$ ) and $\mathrm{RuO}_{2}\left(52 \mathrm{mV} \mathrm{dec}{ }^{-1}\right)$. These values were smaller as compared to that measured on RDE, suggesting faster OER kinetics of the electrodeposit on graphite.

Supplementary Table 1 summarizes the detailed performances of some reported state-of-the-art OER catalysts including $\mathrm{Au}$ foam-supported FeCoW, GO-supported NiFe-layered double hydroxide (LDH), $\mathrm{RuO}_{2}, \mathrm{IrO}_{2}$, and $\mathrm{Ir} / \mathrm{C}^{7,27,41-43}$. The comparison indicates that the $\mathrm{NiCeO}_{x} \mathrm{H}_{y} / \mathrm{G}$ hybrid outperforms most of the previous advanced OER catalysts, in terms of widely used figures of merit such as onset potential, overpotential at $10 \mathrm{~mA} \mathrm{~cm}^{-2}$, ECSA-based specific activity at overpotential of $270 \mathrm{mV}$, mass activity, turnover frequency (TOF), and Tafel slope ${ }^{42}$. In a recent report, $\mathrm{NiCeO}_{x}$ supported on $\mathrm{Au}$ exhibited striking activity due to the beneficial effect of $\mathrm{Au}^{29}$. We show here $\mathrm{Au}$ is not indispensable but instead, graphitic substrates give rise to even better performance in affording $\mathrm{Ni}-\mathrm{Ce}$ electrodeposit. Additionally, we investigated the effect of $\mathrm{Ni}$ :Ce molar ratio on the electrocatalytic performance of the hybrid and found a optimized composition of 9Ni:Ce (Supplementary Fig. 22). Furthermore, electrochemical tests of the electrodeposited $\mathrm{NiFeO}_{x} \mathrm{H}_{y} / \mathrm{G}$ and $\mathrm{Co}(\mathrm{OH})_{2} / \mathrm{G}$ samples indicate respectable OER performance of the $\mathrm{NiFe}$ hybrid and limited catalytic activity of Co-based hydroxide catalysts (Supplementary Fig. 23).
Besides activity, the long-term durability of OER catalysts at high currents (ca. $1000 \mathrm{~mA} \mathrm{~cm}^{-2}$ level) is required for practical application such as electrolyzers. The $\mathrm{NiCeO}_{x} \mathrm{H}_{y} / \mathrm{G}$ with a loading mass of $10 \mathrm{mg} \mathrm{cm}^{-2}$ exhibits excellent stability, withstanding constant current of $1000 \mathrm{~mA} \mathrm{~cm}^{-2}$ over $300 \mathrm{~h}$ (Fig. 5e). We observed homogenous bubble formation on electrode surface and rigorous gas release without catalyst peeling off (Supplementary Movie 1). The chapped morphology, porous texture, and particle size were well retained after durability testing, inspite of the loss of the mossy particles on the surface of the electrode (Fig. 5e inset and Supplementary Fig. 24). A post compositional investigation of the electrode revealed almost unchanged $\mathrm{Ni}$ :Ce ratio in $\mathrm{NiCeO}_{x} \mathrm{H}_{y}$ (Supplementary Fig. 24d) and undetectable metal leaching in $\mathrm{KOH}$ electrolyte after the OER tests. Furthermore, the mechanical stability of $\mathrm{NiCeO}_{x} \mathrm{H}_{y} / \mathrm{G}$ electrode was proved by its robustness against ultrasonic treatment (Supplementary Fig. 25).

To gain insight into the electrocatalytic behaviors, we performed in situ Raman and XRD analysis of the electrodeposited electrodes in $1 \mathrm{M} \mathrm{KOH}$. Raman spectra reveal a clear change of the electrodes after being immersed in alkaline electrolyte (Fig. 6a, b) as compared to their pristine states (Supplementary Fig. 16). There is a decrease of intensity of $\mathrm{NO}_{3}{ }^{-}$ peak, suggesting the replacement of $\mathrm{NO}_{3}^{-}$with $\mathrm{OH}^{-}$. For $\mathrm{Ni}$ $(\mathrm{OH})_{2}$ (Fig. 6a), the Ni-O vibration shifts from 463 to $447 \mathrm{~cm}^{-1}$ at open circuit potential (OCP). With increasing electrode potential, a new peak emerges at $494 \mathrm{~cm}^{-1}$ and its intensity increases, indicative of enhanced crystallinity. At potentials above $1.36 \mathrm{~V}$, the $\mathrm{Ni}-\mathrm{O}$ vibration weakens while the $\mathrm{O}-\mathrm{H}$ vibration ascribed to $\alpha-\mathrm{Ni}(\mathrm{OH})_{2}$ varies at $3580-3668 \mathrm{~cm}^{-1}$. The appearance of the characteristic peak at $3580 \mathrm{~cm}^{-1}$ indicates the conversion of $\alpha$ - to $\beta-\mathrm{Ni}(\mathrm{OH})_{2}{ }^{44}$. At $1.41 \mathrm{~V}, \mathrm{Ni}(\mathrm{OH})_{2}$ is transformed into $\gamma-\mathrm{NiOOH}$, as viewed from the characteristic peaks (474 and $\left.554 \mathrm{~cm}^{-1}\right)^{45}$.

Interestingly, $\mathrm{NiCeO}_{x} \mathrm{H}_{y}$ shows much different spectroscopic and electrochemical behaviors (Fig. 6b). Signals associated with $a-\mathrm{Ni}(\mathrm{OH})_{2}$ are almost not discernable. Additionally, the $\gamma-\mathrm{NiOOH}$ phase appears at $1.27 \mathrm{~V}, 0.14 \mathrm{~V}$ lower than the conversion potential of $\mathrm{Ni}(\mathrm{OH})_{2}$. These results indicate that $\gamma-\mathrm{NiOOH}$ is the active phase for the OER, in agreement with previous investigations on nickel hydroxides ${ }^{7,29}$. The formation of $\mathrm{NiOOH}$ after OER was also proved by the FTIR (Supplementary Fig. 26). While neat $\mathrm{CeO}_{2}$ remains unchanged during the OER (Supplementary Fig. 27), the incorporation of Ce in $\mathrm{Ni}-\mathrm{Ce}$ would reduce the barrier energy of $\mathrm{Ni}(\mathrm{II})-\mathrm{Ni}(\mathrm{III})$ transformation and result in lower OER overpotentials. The higher Faraday efficiency of OER on $\mathrm{NiCeO}_{x} \mathrm{H}_{y}$ electrode relative to $\mathrm{Ni}(\mathrm{OH})_{2}$ electrode (Supplementary Fig. 28) further suggest the beneficial effect of $\mathrm{Ce}$ in promoting the formation of electrocatalytically active $\mathrm{Ni}(\mathrm{III})$ species.

To further probe the structural evolution during the OER process, we performed an operando XRD analysis of $\mathrm{Ni}(\mathrm{OH})_{2}$ and $\mathrm{NiCeO}_{x} \mathrm{H}_{y}$. Nickel foam was employed as the catalyst support to exclude the masking effect of the graphitic substrate. In contrast to the amorphous state of pristine $\mathrm{Ni}(\mathrm{OH})_{2}$ and $\mathrm{NiCeO}_{x} \mathrm{H}_{y}$ powders, the electrodes show considerable crystallinity after shortly aging in $1 \mathrm{M} \mathrm{KOH}$ electrolyte. At applied potentials, the $\mathrm{Ni}(\mathrm{OH})_{2}$ electrode occurs mainly in $\gamma$ - NiOOH phase with a small portion of $\beta-\mathrm{Ni}(\mathrm{OH})_{2}$ (Fig. 6c). For the $\mathrm{NiCeO}_{x} \mathrm{H}_{y}$ electrode, only $\gamma$-NiOOH phase is discernable (Fig. 6d), in consistent with the Raman analysis. Note that $\gamma-\mathrm{NiOOH}$ exposes merely (003) facets in $\mathrm{NiCeO}_{x} \mathrm{H}_{y}$, as compared to the preferential (006) planes in $\mathrm{Ni}(\mathrm{OH})_{2}$. The interplanar spacings of $(003)$ and (006) planes are 0.69 and $0.34 \mathrm{~nm}$, respectively. We propose that larger lattices favor the ionic intercalation of $\mathrm{OH}^{-}$and the exposure of more active sites for oxygen evolving (Fig. 6e), which 

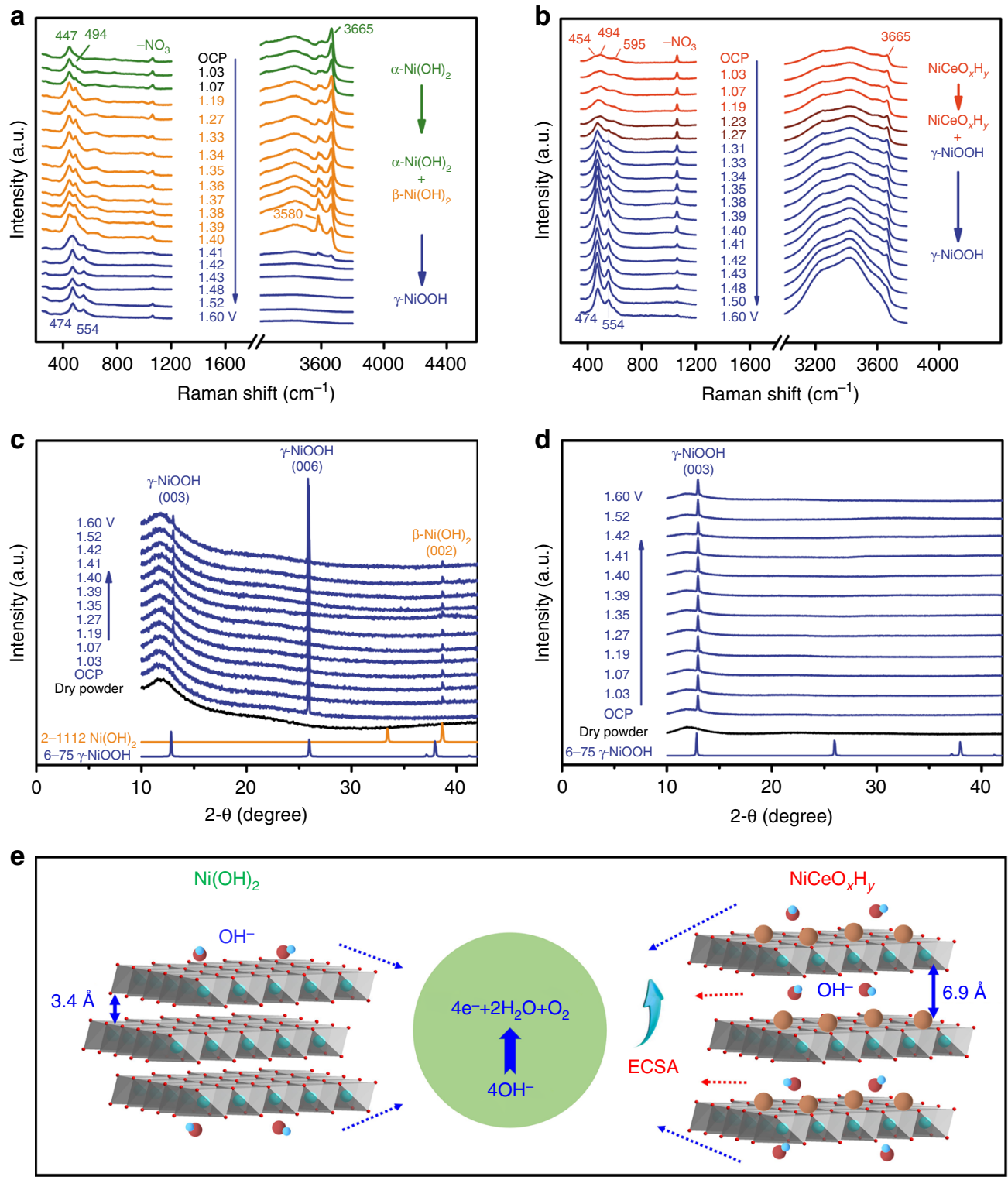

Fig. $6 \mathrm{OER}$ mechanism studies. a, b In situ Raman spectra collected on (a) $\mathrm{Ni}(\mathrm{OH})_{2} / \mathrm{G}$ and (b) $\mathrm{NiCeO}_{x} \mathrm{H}_{y} / \mathrm{G}$ electrodes from open circuit potential (OCP) to $1.6 \mathrm{~V}$ (vs. RHE) in $1 \mathrm{M} \mathrm{KOH}$. c, d Operando XRD patterns collected on (c) $\mathrm{Ni}(\mathrm{OH})_{2} / \mathrm{NF}$ and (d) $\mathrm{NiCeO}_{x} \mathrm{H}_{y} / \mathrm{NF}$ electrodes at different potentials. Data of pristine dry powders and standard profiles of $\mathrm{Ni}(\mathrm{OH})_{2}$ and $\mathrm{NiOOH}$ are shown for reference. e Cartoon showing that the OER proceeds more favorably on $\mathrm{NiCeO}_{x} \mathrm{H}_{y}$ with larger interlamellar spacing and higher ECSA relative to $\mathrm{Ni}(\mathrm{OH})_{2}$

is confirmed by the fivefold increase of ECSA from $\mathrm{Ni}(\mathrm{OH})_{2}$ to $\mathrm{NiCeO}_{x} \mathrm{H}_{y}$ (Supplementary Fig. 18f). Besides, for $\mathrm{NiCeO}_{x} \mathrm{H}_{y}$, the $\mathrm{Ni}-\mathrm{Ce}$ electronic interaction evidenced from FTIR, Raman, and XPS (Fig. 4c-f and Supplementary Fig. 16) is an important factor in enhancing the catalytic activity of nickel hydroxide, since previous density functional theory calculations have demonstrated that the introduction of Ce can modify the binding energy of intermediates (e.g., $\mathrm{HO}^{\star}, \mathrm{O}^{\star}$, and $\mathrm{HOO}^{\star}$ ) involved in the OER and thereby reduce the overpotentials ${ }^{28}$.

\section{Discussion}

We have developed a universally applicable, environmentally benign, and easily scalable electrosynthesis method to prepare a variety of metal (e.g., alkaline earth metals, $3 d$ transition metals and lanthanides) hydroxides/oxides on different substrates. Metal hydroxides are cathodically electrodeposited by increasing local $\mathrm{pH}$ via oxyacid anion reduction reactions. In a peculiar nitrate- assisted electrodeposition, graphitic substrates are found to allow support-deposit interface engineering because of anion intercalation into the graphene layers. The synthesis generates hydroxides or bimetallic hydroxide/oxide hybrids on graphite electrodes with strong adherence, rimous texture, superhydrophilicity, and high mass loading up to $23 \mathrm{mg} \mathrm{cm}^{-2}$. Particularly, the Ni-Ce hybrid co-deposited on graphite features a mosaic structure that consists of uniformly distributed ultrasmall $\mathrm{CeO}_{2}$ nanoparticles in amorphous $\mathrm{Ni}(\mathrm{OH})_{2}$ matrix. This strategy may be extended to preparing other functional materials on conducting layer-structured electrodes to reinforce the integration, loading, conductivity, and mechanical robustness, which are prerequisite in electrochemical devices such as electrolyzers, batteries, and supercapacitors. Preliminary investigations on the oxygen reduction reaction properties of $\mathrm{Mn}_{3} \mathrm{O}_{4}$ (Supplementary Fig. 29) and supercapacitive performance of $\mathrm{Ni}(\mathrm{OH})_{2}$ (Supplementary Fig. 30) suggest wide applicability of the electrodeposited materials. 
As a typical application, we showcase the obtained graphitesupported Ni-Ce composite electrode in catalyzing the technologically important OER reaction. The catalytic performance is superior to the state-of-the-art $\mathrm{RuO}_{2}, \mathrm{IrO}_{2}$, and other reported champion catalysts, exhibiting an overpotential of $177 \mathrm{mV}$ at $10 \mathrm{~mA} \mathrm{~cm}^{-2}$ and sustaining over $300 \mathrm{~h}$ stability at large current of $1000 \mathrm{~mA} \mathrm{~cm}^{-2}$. The high activity and durability render the graphite-supported $\mathrm{Ni}-\mathrm{Ce}$ hybrid a promising inexpensive, yet efficient catalyst for industrial electrolyzer. We further unravel that the integration of $\mathrm{Ce}$ in $\mathrm{Ni}$ hydroxide modulates the electronic structure of $\mathrm{Ni}$ and promotes the formation of $\gamma-\mathrm{NiOOH}$ with preferentially exposed (003) facets that favor the OER due to enhanced ECSA. These findings may aid in the rational design of advanced transition metal hydro(oxy)oxide/oxide electrodes.

\section{Methods}

Materials. All reagents and solvents used were of analytical grade. Substrates were described as follows: graphite sheet (thickness: $1.0 \mathrm{~mm}$, bulk density: $1.85 \mathrm{~g} \mathrm{~cm}^{-3}$, supplied from Gaofeng), nickel foam (thickness: $1.5 \mathrm{~mm}$, areal density: $0.035 \mathrm{~g} \mathrm{~cm}^{-2}$, Jiayisheng), carbon paper (thickness: $0.20 \mathrm{~mm}$, bulk density: $0.78 \mathrm{~g} \mathrm{~cm}^{-3}$, Toray), titanium sheet (thickness: $0.20 \mathrm{~mm}$, Shuanghua), copper foil (thickness: $0.05 \mathrm{~mm}$, Feintool), indium tin oxide and fluorine-doped tin oxide (thickness: $1.1 \mathrm{~mm}$, Weslsy), and GC sheet (thickness: $1 \mathrm{~mm}$, Aida).

Materials synthesis. Electrodeposition was performed at $25^{\circ} \mathrm{C}$ in a $50 \mathrm{ml} \mathrm{elec}$ trolytic bath. A conducting substrate (GC, $\mathrm{CP}, \mathrm{NF}, \mathrm{Ti}$, graphite, etc.), a graphite plate, and a saturated calomel electrode (SCE) served as the working, counter and reference electrode, respectively. The electrolyte was an aqueous nitrate solution containing 0.1 $\mathrm{M}$ total metal ions. The bath, graphite plate, and all substrates were ultrasonically cleaned in $1 \mathrm{M} \mathrm{HCl}$ and Millipore water $\left(18.2 \mathrm{M} \Omega \mathrm{cm}^{-1}\right)$. In a typical synthesis, the graphite substrate was first subjected to anodic treatment at $20 \mathrm{~mA} \mathrm{~cm}^{-2}$ for $600 \mathrm{~s}$ to allow $\mathrm{NO}_{3}{ }^{-}$intercalation and then applied to a cathodic deposition at $-20 \mathrm{~mA} \mathrm{~cm}^{-2}$ for $600 \mathrm{~s}$. On non-graphitic substrates such as bare GC, CP, NF, and $\mathrm{Ti}$, direct cathodic electrodeposition was performed at current of $-20 \mathrm{~mA} \mathrm{~cm}^{-2}$ for $300 \mathrm{~s}$. For $3 \mathrm{D}$ substrates like CP and NF, an ultrasonic pretreatment of $600 \mathrm{~s}$ was applied to ensure electrolyte soaking.

For comparison, $\mathrm{NiCeO}_{x} \mathrm{H}_{y}$ in thin film form was also electrodeposited onto GC electrode following similar procedures described above (current $1.2 \mathrm{~mA}$, duration $55 \mathrm{~s}$ ). The GC substrate was modified with a graphite layer to enhance adhering of deposit. To prepare graphite-modified GC electrode, $10 \mathrm{mg}$ of graphite powder (Sigma-Aldrich) was dispersed in $950 \mu \mathrm{l}$ of isopropanol and $50 \mu \mathrm{l}$ of Nafion solution ( $5 \mathrm{wt} \%$ in water, Sigma-Aldrich). The resultant suspension was then sonicated for $30 \mathrm{~min}$ to form a homogenous ink. An aliquot of $5 \mu \mathrm{l}$ of this ink was afforded on GC and dried in air. The loading amount of deposited $\mathrm{NiCeO}_{x} \mathrm{H}_{y}$ on GC electrode was around $0.2 \mathrm{mg} \mathrm{cm}^{-2}$, as determined by electrochemical quartz crystal microbalance (EQCM).

Materials characterizations. SEM images were collected with a JEOL JEM-7500F field-emission electron microscope. TEM equipped with EDS and SAED was carried out in a JEOL 2010F $200 \mathrm{keV}$ field-emission electron microscope. Powder $\mathrm{XRD}$ measurements were conducted on a Rigaku rotating anode diffractometer with a monochromated $\mathrm{Cu} \mathrm{Ka} \mathrm{X-ray} \mathrm{source.} \mathrm{Fourier-transform} \mathrm{infrared} \mathrm{spectra}$ were measured using a Bruker Vertex 70 FT-IR spectrometer. Raman spectra for powder samples were collected using a Horiba LabRAM HR Evolution microscope with an acquisition time of $20 \mathrm{~s}$. XPS data were collected using a Kratos Axis Ultra DLD spectrometer employing a monochromated Al-Ka X-ray source.

Electrochemistry tests. Electrochemical measurements were performed on Par stat 4000 potentiostat/galvanostat workstation (AMETEK) and Ivium-n-State multichannel electrochemical analyser (IVIUM), using a three-electrode system with deposited hydroxides, $\mathrm{Pt}$ sheet, and $\mathrm{Hg} / \mathrm{HgO}$ as the working, counter, and reference electrode, respectively. All potentials are reported relative to the reversible hydrogen electrode (RHE) scale unless noted. A consistent solution resistance of $0.5 \Omega$ was measured via electrochemical impedance spectroscopy under OCP and was used for iR correction.

The Faradaic efficiency was calculated from the total amount of oxygen produced and the total charge $(Q)$ passed through the electrolytic cell. The total amount of produced oxygen was measured by a drainage method. Assuming that four electrons are needed to produce one $\mathrm{O}_{2}$ molecule, the Faradaic efficiency can be calculated as follows ${ }^{26}$ :

$$
\eta_{\mathrm{O}_{2}}=\frac{4 F * \mathrm{n}}{Q}
$$

where $F$ is the Faraday constant $\left(96,485 \mathrm{C} \mathrm{mol}^{-1}\right)$ and $n$ is the number of moles of generated $\mathrm{O}_{2}$.
EQCM measurements were performed on a QCM922 (Princeton Applied Research) with a two-electrode configuration. An AT-cut platinum-coated quartz crystal of $8.985 \mathrm{MHz}$ resonance frequency with the geometrical area of $0.196 \mathrm{~cm}^{2}$ was used as the working electrode, and a platinum plate as the counter electrode. An aqueous solution containing $0.1 \mathrm{M}$ metal ions was used as the electrolyte. The electrodeposition was performed at room temperature in galvanostatic mode at $-1.2 \mathrm{~mA}$ for $55 \mathrm{~s}$ and the corresponding change in resonance frequency was measured. The change in mass per unit area was calculated from the change in resonance frequency using the Sauerbrey equation.

The TOF value was calculated using the following equation ${ }^{7}$ :

$$
\mathrm{TOF}=\frac{J * A}{4 * F * m}
$$

where $J\left(\mathrm{~A} \mathrm{~cm}^{-2}\right)$ is the current density at a given overpotential (e.g., $\eta=270 \mathrm{mV}$ ), $A$ is the surface area of the electrode $\left(0.2475 \mathrm{~cm}^{2}\right), F$ is the Faraday constant $\left(96,485 \mathrm{C} \mathrm{mol}^{-1}\right)$, and $m$ is the number of moles of metal on the electrode. The metal content of $\mathrm{Ni}(\mathrm{OH})_{2}(56 \mathrm{wt} \% \mathrm{Ni})$ and $\mathrm{NiCeO}_{x} \mathrm{H}_{y}(46 \mathrm{wt} \% \mathrm{Ni}$ and $11.8 \mathrm{wt} \% \mathrm{Ce})$ was quantified by ICP-MS. Because Ni is much more active than Ce for the OER catalysis in alkaline solution, $\mathrm{Ni}$ atoms are supposed to be the active sites for both $\mathrm{Ni}(\mathrm{OH})_{2}$ and $\mathrm{NiCeO}_{x} \mathrm{H}_{y}$ during the TOF calculation.

In situ Raman spectra and operando XRD measurements. In situ Raman spectra were acquired under controlled potentials using a homemade cell, which consisted of a working electrode (electrodeposit on $3 \mathrm{~mm}$ graphite) at the top, a $\mathrm{Pt}$ wire counter electrode and a $\mathrm{Ag} / \mathrm{AgCl}$ (saturated $\mathrm{KCl}$ ) reference electrode. Raman spectra were collected using a confocal microscope (Horiba LabRAM HR Evolution) with an excitation wavelength of $633 \mathrm{~nm}$, a power of 1-3 $\mathrm{mW}$, and a spectral resolution of $\sim 1 \mathrm{~cm}^{-1}$. The spot size of the laser beam was estimated to be $1-2 \mu \mathrm{m}$. Acquisition time was typically $20 \mathrm{~s}$ for the spectral window of $1100 \mathrm{~cm}^{-1}$. Spectral shifts were calibrated routinely against the value of a silicon wafer $\left(520.7 \mathrm{~cm}^{-1}\right)$. The working electrode was anodically scanned from open circuit potential to $1.6 \mathrm{~V}$ at a rate of $0.2 \mathrm{mV} \mathrm{s}^{-1}$. Operando XRD measurements were conducted on Rigaku diffractometer at room temperature using the same cell. Diffraction data were collected with speed of $20^{\circ} \mathrm{min}^{-1}$ at $2 \theta$ range of $10-43^{\circ}$.

Data availability. The authors declare that all the relevant data are available within the paper and its Supplementary Information file or from the corresponding author upon reasonable request.

Received: 4 March 2018 Accepted: 22 May 2018 Published online: 18 June 2018

\section{References}

1. Yang, F. Y. et al. Large magnetoresistance of electrodeposited single-crystal bismuth thin films. Science 284, 1335-1337 (1999).

2. Therese, G. H. A. \& Kamath, P. V. Electrochemical synthesis of metal oxides and hydroxides. Chem. Mater. 12, 1195-1204 (2000).

3. Li, X. H., Pletcher, D. \& Walsh, F. C. Electrodeposited lead dioxide coatings. Chem. Soc. Rev. 40, 3879-3894 (2011).

4. Liu, Y. H., Gokcen, D., Bertocci, U. \& Moffat, T. P. Self-terminating growth of platinum films by electrochemical deposition. Science 338, 1327-1330 (2012).

5. Mahenderkar, N. K. et al. Epitaxial lift-off of electrodeposited single-crystal gold foils for flexible electronics. Science 355, 1203-1206 (2017).

6. Chen, G. Z., Fray, D. J. \& Farthing, T. W. Direct electrochemical reduction of titanium dioxide to titanium in molten calcium chloride. Nature 407, 361-364 (2000).

7. Lu, X. Y. \& Zhao, C. Electrodeposition of hierarchically structured threedimensional nickel-iron electrodes for efficient oxygen evolution at high current densities. Nat. Commun. 6, 6616 (2015).

8. Morales-Guio, C. G., Liardet, L. \& Hu, X. L. Oxidatively electrodeposited thin-film transition metal (oxy)hydroxides as oxygen evolution catalysts. J. Am. Chem. Soc. 138, 8946-8957 (2016).

9. Li, H. B. et al. Amorphous nickel hydroxide nanospheres with ultrahigh capacitance and energy density as electrochemical pseudocapacitor materials. Nat. Commun. 4, 1894 (2013).

10. Hassoun, J., Panero, S., Simon, P., Taberna, P. L. \& Scrosati, B. High-rate, long-life Ni-Sn nanostructured electrodes for lithium-ion batteries. $A d v$. Mater. 19, 1632-1635 (2007).

11. Zhang, H. G. et al. Electroplating lithium transition metal oxides. Sci. Adv. 3 e1602427 (2017).

12. Sieradzki, K., Brankovic, S. R. \& Dimitrov, N. Electrochemical defect-mediated thin-film growth. Science 284, 138-141 (1999).

13. Heerman, L. \& Tarallo, A. Theory of the chronoamperometric transient for electrochemical nucleation with diffusion-controlled growth. J. Electroanal. Chem. 470, 70-76 (1999). 
14. Budevski, E., Staikov, G. \& Lorenz, W. J. Electrocrystallization, nucleation and growth phenomena. Electrochim. Acta 45, 2559-2574 (2000).

15. Datta, M. \& Landolt, D. Fundamental aspects and applications of electrochemical microfabrication. Electrochim. Acta 45, 2535-2558 (2000).

16. Parker, J. F. et al. Rechargeable nickel-3D zinc batteries: an energy-dense, safer alternative to lithium-ion. Science 356, 415-418 (2017).

17. Zhang, H. G., Yu, X. D. \& Braun, P. V. Three-dimensional bicontinuous ultrafast-charge and-discharge bulk battery electrodes. Nat. Nanotechnol. 6, 277-281 (2011).

18. Sun, H. T. et al. Three-dimensional holey-graphene niobia composite architectures for ultrahigh-rate energy storage. Science 356, 599-604 (2017)

19. Suntivich, J., May, K. J., Gasteiger, H. A., Goodenough, J. B. \& Shao-Horn, Y. A perovskite oxide optimized for oxygen evolution catalysis from molecular orbital principles. Science 334, 1383-1385 (2011).

20. Oh, S. H., Black, R., Pomerantseva, E., Lee, J. H. \& Nazar, L. F. Synthesis of a metallic mesoporous pyrochlore as a catalyst for lithium- $\mathrm{O}_{2}$ batteries. Nat. Chem. 4, 1004-1010 (2012).

21. Wang, H. T. et al. Bifunctional non-noble metal oxide nanoparticle electrocatalysts through lithium-induced conversion for overall water splitting. Nat. Commun. 6, 7261 (2015).

22. Blasco-Ahicart, M., Soriano-López, J., Carbó, J. J., Poblet, J. M. \& GalanMascaros, J. R. Polyoxometalate electrocatalysts based on earth-abundant metals for efficient water oxidation in acidic media. Nat. Chem. 10, 24-30 (2018).

23. Cheng, F. Y. et al. Rapid room-temperature synthesis of nanocrystalline spinels as oxygen reduction and evolution electrocatalysts. Nat. Chem. 3, 79-84 (2011)

24. Zheng, X. L. et al. Theory-driven design of high-valence metal sites for water oxidation confirmed using in situ soft X-ray absorption. Nat. Chem. 10, 149-154 (2018).

25. Smith, R. D. L., Prevot, M. S., Fagan, R. D., Trudel, S. \& Berlinguette, C. P. Water oxidation catalysis: electrocatalytic response to metal stoichiometry in amorphous metal oxide films containing iron, cobalt, and nickel. J. Am. Chem. Soc. 135, 11580-11586 (2013).

26. Zhang, B. et al. Homogeneously dispersed multimetal oxygen-evolving catalysts. Science 352, 333-337 (2016).

27. Subbaraman, R. et al. Trends in activity for the water electrolyser reactions on 3d M(Ni,Co,Fe,Mn) hydr(oxy)oxide catalysts. Nat. Mater. 11, 550-557 (2012).

28. Ng, D. J. W. et al. Gold-supported cerium-doped $\mathrm{NiO}_{\mathrm{x}}$ catalysts for water oxidation. Nat. Energy 1, 16053 (2016)

29. Dionigi, F. \& Strasser, P. NiFe-based (oxy)hydroxide catalysts for oxygen evolution reaction in non-acidic electrolytes. Adv. Energy Mater. 6, 1600621 (2016).

30. Batchellor, A. S. \& Boettcher, S. W. Pulse-electrodeposited Ni-Fe (oxy) hydroxide oxygen evolution electrocatalysts with high geometric and intrinsic activities at large mass loadings. ACS Catal. 5, 6680-6689 (2015)

31. Chen, Y. et al. Highly active, nonprecious electrocatalyst comprising borophene subunits for the hydrogen evolution reaction. J. Am. Chem. Soc. 139, 12370-12373 (2017).

32. Pourbaix, M. Atlas of Electrochemical Equilibria in Aqueous Solutions. (Pergamon Press, Oxford, 1966).

33. Forsman, W. C., Vogel, F. L., Carl, D. E. \& Hoffman, J. Chemistry of graphite intercalation by nitric acid. Carbon 16, 269-271 (1978).

34. Song, F. \& Hu, X. L. Exfoliation of layered double hydroxides for enhanced oxygen evolution catalysis. Nat. Commun. 5, 5477 (2014).

35. Fu, X. Z. et al. Physical characterization, electrochemical performance and storage stability of spherical Al-substituted $\gamma-\mathrm{NiOOH}$. Electrochim. Acta 52, 2109-2115 (2007).

36. Brussino, P., Bortolozzi, J. P., Milt, V. G., Banús, E. D. \& Ulla, M. A. $\mathrm{NiCe} / \gamma-\mathrm{Al}_{2} \mathrm{O}_{3}$ coated onto cordierite monoliths applied to oxidative dehydrogenation of ethane (ODE). Catal. Today 273, 259-265 (2016).

37. Mansour, A. N. \& Melendres, C. A. Characterization of $a-\mathrm{Ni}(\mathrm{OH})_{2}$ by XPS. Surf. Sci. Spectra 3, 255-262 (1994).
38. Mansour, A. N. \& Melendres, C. A. Characterization of electrochemically prepared $\gamma$-NiOOH by XPS. Surf. Sci. Spectra 3, 271-278 (1994).

39. Bêche, E., Charvin, P., Perarnau, D., Abanades, S. \& Flamant, G. Ce 3d XPS investigation of cerium oxides and mixed cerium oxide $\left(\mathrm{Ce}_{\mathrm{x}} \mathrm{Ti}_{\mathrm{y}} \mathrm{O}_{\mathrm{z}}\right)$. Surf. Interface Anal. 40, 264-267 (2008).

40. Louie, M. W. \& Bell, A. T. An investigation of thin-film Ni-Fe oxide catalysts for the electrochemical evolution of oxygen. J. Am. Chem. Soc. 135, 12329-12337 (2013).

41. Long, X. et al. A strongly coupled graphene and FeNi double hydroxide hybrid as an excellent electrocatalyst for the oxygen evolution reaction. Angew. Chem. Int. Ed. 53, 7584-7588 (2014).

42. McCrory, C. C. L. et al. Benchmarking hydrogen evolving reaction and oxygen evolving reaction electrocatalysts for solar water splitting devices. J. Am. Chem. Soc. 137, 4347-4357 (2015).

43. Gong, M. et al. An advanced Ni-Fe layered double hydroxide electrocatalyst for water oxidation. J. Am. Chem. Soc. 135, 8452-8455 (2013).

44. Song, Q. S., Aravindaraj, G. K., Sultana, H. \& Chan, S. L. I. Performance improvement of pasted nickel electrodes with multi-wall carbon nanotubes for rechargeable nickel batteries. Electrochim. Acta 53, 1890-1896 (2007).

45. Klaus, S., Cai, Y., Louie, M. W., Trotochaud, L. \& Bell, A. T. Effects of Fe electrolyte impurities on $\mathrm{Ni}(\mathrm{OH})_{2} / \mathrm{NiOOH}$ structure and oxygen evolution activity. J. Phys. Chem. C 119, 7243-7254 (2015).

\section{Acknowledgements}

This work was supported by the MOST (2017YFA0206700), NSFC (51571125, 21322101, and 21421001), and MOE (B12015).

\section{Author contributions}

F.C. proposed the concept. Z.Y., H.S., X.C., H.Liu, H.Li, Y.Z., and W.X. performed the experiments. Z.Y., F.C., and J.C. co-wrote the manuscript. All authors participated in data analysis and manuscript discussion. F.C. and J.C. directed the research.

\section{Additional information}

Supplementary Information accompanies this paper at https://doi.org/10.1038/s41467018-04788-3.

Competing interests: The authors declare no competing interests.

Reprints and permission information is available online at http://npg.nature.com/ reprintsandpermissions/

Publisher's note: Springer Nature remains neutral with regard to jurisdictional claims in published maps and institutional affiliations.

Open Access This article is licensed under a Creative Commons Attribution 4.0 International License, which permits use, sharing, adaptation, distribution and reproduction in any medium or format, as long as you give appropriate credit to the original author(s) and the source, provide a link to the Creative Commons license, and indicate if changes were made. The images or other third party material in this article are included in the article's Creative Commons license, unless indicated otherwise in a credit line to the material. If material is not included in the article's Creative Commons license and your intended use is not permitted by statutory regulation or exceeds the permitted use, you will need to obtain permission directly from the copyright holder. To view a copy of this license, visit http://creativecommons.org/ licenses/by/4.0/

(C) The Author(s) 2018 